Jurnal Keperawatan Padjadjaran

ISSN 2338-5324 (print)

ISSN 2442-7276 (online)

Online di http://jkp.fkep.unpad.ac.id

DOI : $10.24198 / \mathrm{jkp}$

\title{
The Effect of Brain Game on Cognitive Function in Stroke Patients
}

\author{
Novi Malisa*, Yuke Kirana \\ Nursing Academy, Dustira Hospital, Cimahi, Indonesia \\ Corresponding Email: novimalisa53@gmail.com
}

Received: 16-10-2020 Revised: 03-04-2021 Accepted: 12-04-2021

\begin{abstract}
The decline in cognitive function has been a disorder frequently experienced by stroke patients. The present study aimed to determine the effect of android-based brain games on cognitive function in stroke patients. Brain games in this study are designed using an exploratory approach to various cognitive function domains that are damaged. The quasi experiment using two groups pretest and posttest design involved 15 individuals for each group recruited from a hospital in West Java through purposive sampling with a sample calculation formula using a paired numerical analytical research formula. The intervention group received an android-based brain games three times a week for one month, the control group received placebo intervention (mentioning colors of different words) three times a week for one month. The FACT-Cog Version 3 questionnaire utilized as the measuring instrument. Measurements were taken every week after the intervention for one month. The results indicated that there was a significant change in cognitive function scores before and after the intervention in the intervention group $(p=0.000)$. Meanwhile, in the control group there is no significant change $(\mathrm{p}=0.164)$. Moreover, the results of cognitive function score analysis after intervention between the intervention and control group exhibit a significant difference $(p=0.000)$. The brain game intervention has a significant effect on cognitive function after the third treatment in the first week $(p<0.05)$. Also, the results exhibit the potential effect of brain games on the cognitive function level of stroke patients. Some of the things that make the intervention in this study effective in improving cognitive function are that the respondents included in this study are only those who have a score greater than or equal to 46, which may be different when applied to patients with lower scores. In addition, the intervention was carried out on respondents who had experienced a stroke for the first time and may be different if applied to people who have had several strokes. Therefore, it is important to expand the criteria for respondents in further research. Furthermore, this can be used as an option of the nursing intervention to manage cognitive problems among stroke patients.
\end{abstract}

Keywords: Brain game, cognitive function, stroke. 
Novi Malisa: The Effect of Brain Game on Cognitive Function in Stroke Patients

\section{Introduction}

Stroke is classically characterized as a neurological deficit attributed to an acute focal injury of the central nervous system (CNS) by a vascular cause, including cerebral infarction, intracerebral haemorrhage (ICH), and subarachnoid haemorrhage (SAH), and is a major cause of disability and death worldwide. (Sacco et al., 2013). Weinstein et al., (2014) mention that individuals with strokes experience weak cognitive function in the immediate recall of logical and visual memory, verbal, language, executive function, and visuospatial and motor skills.

Cognitive function is defined as the ability to understand daily events, make decisions and adapt to the environment (Yoo et al., 2015). The decline in cognitive function resulted from a lack of blood flow to the brain, leading to the hypoxemia to regional area of the brain and causing chain reactions that resulted in the death of brain cells and their constituents. Unfortunately, it is common among stroke patients. Studies found that the incidence of cognitive decline among stroke patients were 20-80\% (Sun et al., 2014). Middleton et al., (2014) reported that cognitive impairment was more common in acute strokes $(76.3 \%)$ compared with chronic stroke $(67.3 \%)(\mathrm{p}=$ 0.09).

The cognitive impairment experienced by stroke patients is identified as lowering the patient's ability to live independently. Early assessment of cognitive impairment is particularly important at the early diagnostic stage (Wulandari \& Ismail, 2019). Study reported that cognitive impairment does not only affect individual coping abilities and daily activities, but also negatively impacts on patients' work and social relationships (O'Connor et al., 2010). World Health Organization (2017) explains that cognitive impairment is a strong predictor of functional ability and the need for care in older people. The annual conversion rate from mild cognitive impairment to Alzheimer's disease or non-specific dementia ranges between $12 \%$ and $15 \%$. Furthermore, Fitriana et al., (2020) in her research found that stroke has a significant relation with the incidence of dementia in adults. This is inseparable from the decline in cognitive function experienced by stroke patients. The complexity of the negative impacts brought about by cognitive impairment causes patients to experience obstacles in carrying out daily activities and results in decreased quality of life (Cheung et al., 2012).

Several domains of cognitive impairment that occurred due to stroke include attention and concentration, memory, executive function and speed of processing (ReidArndt et al., 2010). Harvey (2019) described strategies for assessing the cognitive function domain through tests that could be carried out on each sub-domain of cognitive function. This cognitive assessment can provide clues about the extent of functional deficits and their potential for treatment.

Furthermore, Harvey (2019) explains that the attention domain could be stimulated by visual processing, using the similarity theory approach. Selective attention tasks often provide distraction information and ask the patient to guess expected information. Distractors can be presented in sound forms for auditory tasks and alternatively colors, texts, sizes for visual tasks. The other domain in cognitive function is memory functioning. Manipulation of working memory refers to the process of operating on information stored in working memory storage. The prototypical manipulation of working memory task is digit span backwards, where the participant is asked to recall information in reversed order compared with presentation ("258" $\rightarrow$ " 852 ").

The other domain of cognitive function is the visuospatial domain and executive function. The visuospatial domain is a constructional ability such as drawing or imitating various kinds of images and composing blocks (Sun et al., 2014). The application of this domain stimulation is by arranging a row of blocks bearing numbers. Meanwhile, the executive function is also commonly referred to as reasoning and problem solving. Thus, tasks of problem solving, planning, manipulating mazes, and other complex tasks where management of multiple cognitive abilities are required, fall under the domain of executive functioning (Harvey, 2019). Applications in the executive function tasks are simple logic games such as $1 \ldots . .3=4$, and respondent must choose one of the signs $(+,-$, : or $\mathrm{x})$ to be filled at that blank 
Novi Malisa: The Effect of Brain Game on Cognitive Function in Stroke Patients

space.

Interventions applied to the stroke patients should be fun, light, and not energy-draining since a study reports a strong correlation between decreased cognitive function and stress, anxiety, and fatigue (Cheung et al., 2012). Therefore, the intervention given is expected to reduce stress, improve mood, not be tiring, and reduce anxiety. Cognitive training is one of the non-pharmacological interventions reported to have a good success rate in improving cognitive function both subjectively and objectively after chemotherapy for breast cancer (Chan et al., 2015).

Kesler et al., (2013) studied internet and computer-based cognitive training interventions with a focus on improving the executive function of breast cancer survivors and reported that they significantly improve executive and motor function $(\mathrm{p}=0.008)$, verbal function and language skills $(\mathrm{p}=$ $0.003)$, orientation and attention $(\mathrm{p}=0.009)$, and self-report improvement $(p=0.02)$. Other study on cognitive training interventions was conducted by Chen et al., (2015) in the form of visual training consisting of four modes for stroke patients who had a decreased cognitive function and impaired eye movement for 30 minutes once a day, five times a week, for four weeks. This training proved to be significant in improving attention and concentration, executive function, memory, visual skills, abstract thinking, calculation, and directional force, as well as its total standard score ( $p$ $<0.01)$.

From those two studies, cognitive training effectively improve cognitive function, but in both training patient should have and be able to operate a computer and internet properly. In Indonesia, not everyone has a computer connected to the internet. In addition, visual training requires a therapist to determine which mode is suitable for the patient according to the patient's vision condition.

This becomes the basis for developing intervention media that can be used independently by the patients' families to improve patients' cognitive function. The researchers attempted to develop the androidbased cognitive training which is expected to improve the cognitive function of stroke patients as indicated by improvements in the cognitive domains (attention and concentration, memory, executive function, and speed of processing) (Harvey, 2019). The objective of this study is to determine the effect of Android-based brain games on cognitive function in stroke patients.

\section{Method}

Quasi experiment with two group pre-test and post-test design was used in the present study. The treatment group was given intervention in the form of playing the android-based brain games for 30 minutes once a day, three times a week for one month. The intervention was carried out under the supervision of the researcher while in the hospital and continued with a home visit to the respondent's house for respondents who had been discharged from the hospital. Respondents played brain games independently and the researcher monitored the duration of the game. This game consisted of four games, all of which aim to improve cognitive function by adopting the cognitive domain assessment approach (Harvey, 2019).

The first game was "Attention Game" which was designed based on the visual processing, using the similarity theory approach. The second was "Memory Game", designed using a serial recall task approach. The third was "Visual Game", using constructional theory. In the fourth game, a simple logic game approach called "Executive Functions Game" was applied. These four games were implemented to improve cognitive function, covering several domains i.e. attention, memory, visuospatial, and executive functions. The control group received the provision of a placebo in the form of another type of brain game three times a week for one month (placebo) by watching the Android-based video media, the respondents were asked to read and verbally mentioned a word "written" in different colour. Technically the researcher made a schedule for implementing the intervention to the respondents and the family. Furthermore, the intervention was carried out according to schedule starting from the time the patient underwent treatment at the hospital and continued at home. During the intervention at home, the researcher conducted a home visit 
according to the intervention schedule for each respondent. During the implementation of the intervention, the family also accompanied the respondent to provide motivation and see the respondent's progress during the intervention. Measurement of cognitive function was carried out by the researcher directly every weekend after the intervention for 1 month.

The population of this study included the ischemic stroke patients at one of the hospital in West Java. The purposive sampling was used as the sampling technique with inclusion criteria: 1) Aged $\geq 18$ years, 2) first episode of stroke, 3) have a cognitive dysfunction indicated by score greater or equal to 46 of the FACT-Cog Version 3, 4) Voluntarily join this study.

The determination of the number of samples uses a paired numerical analytical research formula. That formula is $\mathrm{n} 1=\mathrm{n} 2=$ $\left(((Z \alpha+Z \beta) S) /\left(X \quad 1-X \_2\right)\right)^{\wedge} 2-$, where $\mathrm{n}$ is the number of research respondents in each group, $\mathrm{Z} \alpha$ is standard deviation $\alpha$ (type I error is set at 5\% with a two-tail hypothesis), $Z \_\beta$ is standard deviation $\beta$ (type II error is set at $5 \%$ ), X_1- X 2 is the minimum difference between the mean which is considered significant, and $\mathrm{S}$ is the standard deviation of the difference in value between groups (Dahlan, 2013). Based on this formula, the minimum sample size is 13 people for each group. Anticipation of dropout, loss to follow-up and noncompliance of respondents in the process of this research was carried out by correcting the sample size using the formula $n^{\prime}=\square(n /$ (1-f)), where n' is the number of research samples, $\mathrm{n}$ is sample size calculated, and $\mathrm{f}$ is estimated proportion of drop out (15\%). A total of 30 individuals were selected as the sample (15 for each group: intervention and control). Sample group allocation is carried out by utilizing a simple random allocation techniques using a computer random number generator (random.org).

The demographic questionnaire containing gender, date of birth (age), marital status, occupation, religion, latest education, and history of disease as well as the FACT$\mathrm{Cog}$ Version 3 questionnaire were used to collect the data. The researchers have obtained permission to use the FACT-Cog Version 3 questionnaire from the FACIT. This instrument has validity, reliability, and equivalence in good clinical and research studies with a cronbach $\alpha$ value of $0.707-$ 0.929 . The validity value is 0.725 (Cheung et al., 2013).

The researchers have met the required language translation requirements required by FACIT.org such as translating using two independent translators who are tasked with translating from English to Indonesian, sending the translation results to the third translator who is in charge of reviewing English and the two translations directly, choosing one of the three translation results and sending only the results of the translation to the fourth translator to translate back from Indonesian to English (Tyupa, 2011), sending the results of the back-translation step document for review and testing the questionnaire to 10 stroke patients who had cognitive function problems to find out whether the grammar in the translated questionnaire can be understood by the research respondents. The result of this questionnaire test is that all patients can understand the grammar and meaning of the questions in the questionnaire.

The data analysis was conducted using the descriptive and inferential analysis. The paired t-test was carried out to determine the difference in mean scores of pre- and posttest in the intervention and control group. The independent t-test was employed to determine the difference in cognitive function mean scores in the pretest and posttest of intervention and control group as well as to determine the difference between the pretest and posttest cognitive function scores. To determine the effect pattern of Androidbased brain games on cognitive function in the intervention group, the repeated ANOVA and post hoc tests were utilized. This test can reveal a pattern of the effect of intervention given (Dahlan, 2014). The significance level used was $p<0.05$, with a confidence level of $95 \%$. This study was approved by the ethics committee of Jenderal Achmad Yani Institute of Health Science with a letter number : 003/ $\mathrm{KPEK} / \mathrm{I} / 2020$. 
Novi Malisa: The Effect of Brain Game on Cognitive Function in Stroke Patients

\section{Results}

Table 1 Table of Frequency Distribution, Percentage, and Homogeneity Test of Respondent Characteristics of Intervention- and Control Group $(\mathbf{N}=30)$

\begin{tabular}{|c|c|c|c|c|c|}
\hline \multirow{2}{*}{ Characteristic } & \multicolumn{2}{|c|}{$\begin{array}{l}\text { Intervention } \\
\quad(\mathrm{n}=15)\end{array}$} & \multicolumn{2}{|c|}{$\begin{array}{l}\text { Control } \\
(\mathrm{n}=15)\end{array}$} & \multirow{2}{*}{ p Value } \\
\hline & f & $(\%)$ & $\mathbf{f}$ & $(\%)$ & \\
\hline \multicolumn{6}{|l|}{ Age (Years Old) } \\
\hline 36-45 (late adult) & 1 & 6.67 & 3 & 20 & $0.625^{\mathrm{a}}$ \\
\hline 46-55 (early elderly) & 10 & 66.67 & 8 & 53.34 & \\
\hline 56-65 (late elderly) & 3 & 20 & 2 & 13.33 & \\
\hline$>65$ (senior) & 1 & 6.66 & 2 & 13.33 & \\
\hline \multicolumn{6}{|l|}{ Sex } \\
\hline Male & 7 & 46.67 & 8 & 53.33 & $0.716^{\mathrm{a}}$ \\
\hline Female & 8 & 53.33 & 7 & 46.67 & \\
\hline \multicolumn{6}{|l|}{ Working Status } \\
\hline Working & 8 & 53.33 & 9 & 60 & $0.625^{\mathrm{a}}$ \\
\hline Not Working & 7 & 46.67 & 6 & 40 & \\
\hline \multicolumn{6}{|l|}{ Marital Status } \\
\hline Married & 12 & 80 & 12 & 80 & $1.00^{\mathrm{a}}$ \\
\hline Not Married & 3 & 20 & 3 & 20 & \\
\hline \multicolumn{6}{|l|}{ Level of Education } \\
\hline Elementary & 1 & 6.66 & 0 & 0 & $1.00^{\mathrm{b}}$ \\
\hline Junior High school & 4 & 26.67 & 5 & 33.33 & \\
\hline Senior High school & 9 & 60 & 9 & 60 & \\
\hline Diploma/Bachelor Degree & 1 & 6.67 & 1 & 6.67 & \\
\hline \multicolumn{6}{|l|}{ Comorbidity } \\
\hline Yes & 11 & 73.33 & 11 & 73.33 & $1.00^{\mathrm{a}}$ \\
\hline No & 4 & 26.67 & 4 & 26.67 & \\
\hline
\end{tabular}

Table 2 Table of Difference in Mean Score of Cognitive Function of Pretest and Posttest within and Between Intervention and Control Groups $(\mathbf{N}=\mathbf{3 0})$

\begin{tabular}{lllll}
\hline \multicolumn{1}{c}{ Variable } & Mean & SD & T & P \\
\hline $\begin{array}{l}\text { Cognitive Function Score within } \\
\text { group: Intervention group }\end{array}$ & & & & \\
Pretest & 69.67 & 12.915 & -24.231 & $0.000^{\mathrm{a}}$ \\
Posttest & 90.80 & 13.385 & & $0.164^{\mathrm{a}}$ \\
Control group & & & & -1.468 \\
Pretest & 68.73 & 13.689 & & \\
Posttest & 69.00 & 14.338 & & \\
\hline
\end{tabular}


Novi Malisa: The Effect of Brain Game on Cognitive Function in Stroke Patients

\begin{tabular}{|c|c|c|c|c|}
\hline Variable & Mean & SD & $\mathbf{T}$ & $\mathbf{P}$ \\
\hline \multicolumn{5}{|c|}{$\begin{array}{l}\text { Cognitive Function Scores Between } \\
\text { Groups; } \\
\text { Pretest }\end{array}$} \\
\hline Intervention & 69.67 & 12.915 & 0.191 & $0.850^{\mathrm{b}}$ \\
\hline Control & 68.73 & 13.869 & & \\
\hline \multicolumn{5}{|l|}{ Post-Test } \\
\hline Intervention & 90.80 & 13.385 & 4.303 & $0.000^{\mathrm{b}}$ \\
\hline Control & 69.00 & 14.338 & & \\
\hline
\end{tabular}

Note: $a=$ Paired t-test, $b=$ Independent t-test

Table 3 Table of Results of Repeated ANOVA Test On Posttest Cognitive Function Scores of Android-Based Brain Games Treatment in The Intervention Group from The First to The Fourth Week

\begin{tabular}{cccc}
\hline $\begin{array}{c}\text { Intervention Treatment } \\
\text { (Week-) }\end{array}$ & Mean & SD & P \\
\hline 1 & 70.867 & 3.514 & 0.000 \\
2 & 74.60 & 3.344 & \\
3 & 85.60 & 3.319 & \\
4 & 90.80 & 3.456 & \\
\hline
\end{tabular}

Table 4 Table of Results of The Paired Wise Comparison Test of Android-Based Brain Game Posttest in The Intervention Group from The First Week to The Fourth Week

\begin{tabular}{ccccc}
$\begin{array}{c}\text { Comparison of Intervention } \\
\text { Treatment Time of Brain Games } \\
\text { (Week-) }\end{array}$ & $\mathbf{1}$ & $\mathbf{2}$ & $\mathbf{3}$ & $\mathbf{4}$ \\
\hline 1 & & & & \\
2 & $3.733^{*}$ & $-3.733^{*}$ & $-14.733^{*}$ & $-19.933^{*}$ \\
3 & $14.733^{*}$ & $11.000^{*}$ & $-11.000^{*}$ & $-16.200^{*}$ \\
4 & $19.933^{*}$ & $16.200^{*}$ & & $-5.200^{*}$ \\
\hline
\end{tabular}

*) The mean difference is significant $(\mathrm{p}<0.05)$

All of the respondents were able to follow the research process for 1 month without any dropout, most of them belonged to the early elderly age $(60 \%)$, had a working status $(56 \%)$ and had comorbidities (73\%). $80 \%$ of respondents were married with the highest level of education from Senior High $(60 \%)$. The percentage of sex between men and women was balanced in the two groups, as was the status of marriage. The whole data on homogeneous characteristics were seen from the results of the chi-square and fisher's exact homogeneity test $(\mathrm{p}>0.05)$.

The baseline (pre-test) of cognitive function scores in both groups refered to the same condition (homogeneous) as indicated by the results of Levene's homogeneity test ( $p$ $>0.05$ ). The highest mean score of cognitive function in the intervention group was derived from the measurement of cognitive function in the fourth week after treatment, which is 90.80 .

The results of Independent t-test on the pretest cognitive function scores represent no difference in cognitive function scores before the intervention between the intervention and the control group $(p=0.850)$. Therefore, this filtered out any bias from the differences in 
Novi Malisa: The Effect of Brain Game on Cognitive Function in Stroke Patients

baseline cognitive function scores between the two groups.

There was a significant change in cognitive function scores between before and after the intervention in the intervention group $(\mathrm{p}=0.000)$. While in the control group, there was no significant change in cognitive function scores between before and after the intervention $(\mathrm{p}=0.164)$. Morevore, the results of cognitive function score analysis after the intervention between the interventionand control group exhibited a significant difference $(p=0.000)$.

The difference in the mean cognitive function of both groups was negative, meaning that there was an increase in cognitive function scores after the intervention, whereas in the intervention group the cognitive function score was higher $(\Delta=21.13)$. The score was merely 0.27 . Statistically, there was a significant difference in cognitive function scores between the intervention and control group $(\mathrm{p}=0.000)$.

The results of repeated ANOVA tests showed a change in the mean scores of cognitive function in the intervention group after being given brain games intervention 3 times a week for 1 month $(p=0.000)$. Furthermore, the results of the post hoc test showed that the brain game intervention could have a significant effect on cognitive function after the third treatment in the first week $(p<0.05)$. Each measurement revealed a significant difference in cognitive function $(\mathrm{p}<0.05)$.

\section{Discussion}

The results of the study proved that Androidbased brain games have a positive effect on cognitive function. This was supported by the cognitive function scores of the posttest intervention group and the difference in the mean post-test between the intervention group and control groups. Furthermore, the result of ANOVA and post hoc test in this study revealed a pattern of cognitive function improvement over time. The brain games applied in the study were designed with an exploratory approach in various domains including training for the brain which in the previous study was found to be effective in improving the attention and concentration, executive function, working memory, and processing speed (Reid-Arndt et al., 2010). The significant change in cognitive function scores after brain games intervention is in line with the results of research conducted by Al-Thaqib et al., (2018) which stated that computerized cognitive training games improved the domain of cognitive function, including attention and motor speed in normal healthy subject. This study has similarities with research conducted by researchers in using a cognitive training game approach. However, it differs in terms of research subjects that focus on healthy people and the cognitive training games used are computer-based. So it can be concluded that both Android-based and computer-based brain games are proven to have an effect on improving cognitive function both in stroke patients and in healthy people.

Also, this is in line with research conducted by Strobach \& Huestegge (2017) which applies commercial computer-based cognitive training tasks by targeting working memory. The study results showed that the number of respondents with cognitive failures was reduced in the intervention group in contrast to the control group at the posttest. Performance improvements are more noticeable for high performing participants (i.e., magnification effects). The difference between the intervention in this study and the research conducted by the researcher lies in the target focus of the cognitive function domain, which only focuses on working memory. Meanwhile, the intervention in this study involved stimulation in the attention, memory, visuo-spatial, and executive functions domains. Cognitive training can be designed according to the focus of the intervention objectives by using a work approach in the domain to be stimulated. So that it is very possible to develop cognitive games in accordance with the direction of intervention goals.

Based on the results of mean difference in cognitive function scores in the intervention and control groups, there is a significant difference between these scores with $\mathrm{p}=$ 0.000 . The results of repeated ANOVA and post hoc tests showed that the brain game intervention have a significant effect on 
cognitive function after the third treatment in the first week $(p<0.05)$. It is recommended that routine brain game treatment be conducted more than three times, given the results of the study showing that changes in cognitive function scores in the intervention group are seen in the third intervention. This is supported by Kesler et al., (2013) which stated that the increase in cognitive function is seen in the first, second, third, fourth, fifth, and sixth months. The key to successful implementation of brain games lies in its routine of three times a week for one month, regular and continuous implementation so that it can help improve the domain of cognitive function, including increasing attention and concentration, executive function, working memory, and processing speed.

The development of dendrite connections in the brain depends on the activity of the individual in getting impulses from the environment. Dendrites become functional when there is an increase in synaptic strength due to a pair of electrical signals along two different neural pathways. This pair of signals increases the rate of neurotransmitters release in the synaptic cleft and facilitates the transmission of active signals from one neuron to the next. This explains that neurons that initially do not function optimally can be maximized by facilitating the rate of neurotransmitter release, so that signals can propagate easily through active neurons and affect inactive neurons (Lawson, 2013). A person's cognitive function is influenced by the number of active brain cells and how many connections there can be between brain cells. This connection can be enhanced if we practice often to be able to "create meaning" or understand what is being learned. In addition, the brain will receive stimulation well if the source of the stimulation is obtained in many ways, for example through hearing and vision as applied to the brain games in this study.

The effectiveness of Android-based brain games intervention in this study lies in the cognitive function improvement strategy by mixing and matching several techniques used to provide active stimuli in the cognitive domain. In addition to the combination of techniques, visual stimuli are also provided that increase memory use, attention and concentration, speed of processing, and executive function. By improving these domains, especially executive function, there will be improvements in overall cognitive function. Brain neurons will be increasingly stimulated by complex impulses from the stimulation of the cognitive domain at the same time, the work of the brain will be more optimal so that it can improve cognitive function (Lawson, 2013).

Stimulation strengthening is done through an interesting, colorful, and graphic form of game as a strategy to strengthen the stimulus. High patient motivation to continue to participate in the program is one of the keys to the success of the therapy and rehabilitation programs, especially for stroke patients. Burgers et al., (2015) stated that games are important vehicles for learning and behavior change as long as players are motivated to continue playing. Therefore, choosing a game-based intervention that is easy to use and attractive is an important point. This is in line with what Hung et al., (2016) explained that selecting games for rehabilitation based on designed-for-fun video games would be a more economical, more feasible, and much more measured way to provide strong and personal motivation for various stroke patients, especially those who have video gaming experience before.

The results of this study indicate the influence of brain games on the cognitive function level of stroke patients so that they can be used as an independent nursing intervention options in managing stroke patients' cognitive function.

\section{Limitation}

The limitation of this study is that the respondents included in the study were only those who had a score greater than or equal to 46, possibly different when applied to patients with lower scores. In addition, the intervention was carried out on respondents who had experienced a stroke for the first time and may be different if it was applied to people who have had several strokes. Therefore, it is important to expand the criteria for respondents in further research. 
Novi Malisa: The Effect of Brain Game on Cognitive Function in Stroke Patients

\section{Conclusion}

The findings indicate that brain games have a positive effect on cognitive function. The application of brain games as part of nursing care interventions in patients with cognitive dysfunction is a strategy that involves the stimulation of various stimuli from the domains of cognitive function. Additionally, to increase the effectiveness of brain games, it is important to establish a routine play schedule for patients 30 minutes once a day, three times a week so that the simulation of the cognitive function domain takes place simultaneously. The implementation of brain games can be conducted either with a nurse's direction or independently by the patient, considering that the digital brain game application is designed to make it easier for patients to obtain independent training so that it can improve patient self-management as well.

\section{References}

Al-Thaqib, A., Al-Sultan, F., Al-Zahrani, A., Al-Kahtani, F., Al-Regaiey, K., Iqbal, M., \& Bashir, S. (2018). Brain training games enhance cognitive function in healthy subjects. Medical Science Monitor Basic Research, 24. https://doi.org/10.12659/ msmbr.909022

Burgers, C., Eden, A., Van Engelenburg, M. D., \& Buningh, S. (2015). How feedback boosts motivation and play in a brain-training game. Computers in Human Behavior, 48. https://doi.org/10.1016/j.chb.2015.01.038

Chan, R. J., McCarthy, A. L., Devenish, J., Sullivan, K. A., \& Chan, A. (2015). Systematic review of pharmacologic and non-pharmacologic interventions to manage cognitive alterations after chemotherapy for breast cancer. In European Journal of Cancer, 51(4). https://doi.org/10.1016/j. ejca.2014.12.017

Chen, C. X., Mao, R. H., Li, S. X., Zhao, Y. N., $\&$ Zhang, M. (2015). Effect of visual training on cognitive function in stroke patients. International Journal of Nursing Sciences, 2(4), 329-333. https://doi.org/10.1016/j. ijnss.2015.11.002

Cheung, Y. T., Chui, W. K., \& Chan, A. (2012). Neuro-cognitive impairment in breast cancer patients: Pharmacological considerations. In Critical Reviews in Oncology/Hematology, 83(1), 99-111. https://doi.org/10.1016/j. critrevonc.2011.09.001

Cheung, Y. T., Lim, S. R., Shwe, M., Tan, Y. P., \& Chan, A. (2013). Psychometric properties and measurement equivalence of the english and chinese versions of the functional assessment of cancer therapy-cognitive in Asian patients with breast cancer. Value in Health, 16(6). https://doi.org/10.1016/j. jval.2013.06.017

Dahlan, M. S. (2014). Statistik Untuk Kedokteran Dan Kesehatan Deskriptif, Bivariat dan Multivariat. Dilengkapi Alikasi Menggunakan SPSS. (Statistics for Descriptive, Bivariate and Multivariate Medicine and Health. Equipped with SPSS Application) 6th ed. In Salemba Medika.

Fitriana, L. A., Ufamy, N., Anggadiredja, K., Amalia, L., Setiawan, S., \& Adnyana, I. K. (2020). Demographic Factors and Disease History Associated with Dementia among Elderly in Nursing Homes. Jurnal Keperawatan Padjadjaran, 8(2), 121-129. https://doi.org/10.24198/jkp.v8i2.1361

Harvey, P. D. (2019). Domains of cognition and their assessment. Dialogues in Clinical Neuroscience, 21(3), 227-237. https://doi. org/10.31887/DCNS.2019.21.3/pharvey

Hung, Y. X., Huang, P. C., Chen, K. T., \& Chu, W. C. (2016). What do stroke patients look for in game-based rehabilitation: A survey study. Medicine (United States), 95(11). https://doi. org/10.1097/MD.0000000000003032

Kesler, S., Hadi Hosseini, S. M., Heckler, C., Janelsins, M., Palesh, O., Mustian, K., \& Morrow, G. (2013). Cognitive training 
for improving executive function in chemotherapy-treated breast cancer survivors. Clinical Breast Cancer, 13(4), 299-306. https://doi.org/10.1016/j.clbc.2013.02.004

Lawson, A. E. (2013). The nature of scientific reasoning and its neurological substrate. In J.F, Gregory \& E. G., Michael (eds). Handbook of the psychology of science. Springer Pub. Company, LLC.

Middleton, L. E., Lam, B., Fahmi, H., Black, S. E., Mcilroy, W. E., Stuss, D. T., Danells, C., Ween, J., \& Turner, G. R. (2014). Frequency of domain-specific cognitive impairment in sub-acute and chronic stroke. NeuroRehabilitation, 34(2), 305-312. https:// doi.org/10.3233/NRE-131030

O'Connor, M. L., Edwards, J. D., Wadley, V. G., \& Crowe, M. (2010). Changes in mobility among older adults with psychometrically defined mild cognitive impairment. Journals of Gerontology - Series B Psychological Sciences and Social Sciences, 65 B(3), 306316. https://doi.org/10.1093/geronb/gbq003

Reid-Arndt, S. A., Hsieh, C., \& Perry, M. C. (2010). Neuropsychological functioning and quality of life during the first year after completing chemotherapy for breast cancer. Psycho-Oncology, 19(5). https://doi. org/10.1002/pon.1581

Sacco, R. L., Kasner, S. E., Broderick, J. P., Caplan, L. R., Connors, J. J. (Buddy), Culebras, A., Elkind, M. S. V., George, M. G., Hamdan, A. D., Higashida, R. T., Hoh, B. L., Janis, L. S., Kase, C. S., Kleindorfer, D. O., Lee, J.-M., Moseley, M. E., Peterson, E. D., Turan, T. N., Valderrama, A. L., \& Vinters, H. V. (2013). An updated definition of stroke for the 21st century. Stroke, 44(7), 2064-2089. https://doi.org/10.1161/ str.0b013e318296aeca

Sopiyudin Dahlan, M. (2013). Besar Sampel dan Cara Pengambilan Sampel dalam Penelitian Kedokteran dan Kesehatan (Sample Size and Method of Sampling in Medical and Health Research). Salemba
Medika.

Strobach, T., \& Huestegge, L. (2017). Evaluating the effectiveness of commercial brain game training with working-memory tasks. Journal of Cognitive Enhancement, 1(4), 539-558. https://doi.org/10.1007/ s41465-017-0053-0.

Sun, J. H., Tan, L., \& Yu, J. T. (2014). Poststroke cognitive impairment: Epidemiology, mechanisms and management. In Annals of Translational Medicine, 2(8), . https://doi. org/10.3978/j.issn.2305-5839.2014.08.05

Tyupa, S. (2011). A theoretical framework for back-translation as a quality assessment tool. In New Voices in Translation Studies, 7(1), 35-46.

Weinstein, G., Preis, S. R., Beiser, A. S., Au, R., Kelly-Hayes, M., Kase, C. S., Wolf, P. A., \& Seshadri, S. (2014). Cognitive performance after stroke - The framingham heart study. International Journal of Stroke, 9(A100). https://doi.org/10.1111/ijs.12275

World Health Organization [WHO]. (2017). Evidence profile: Cognitive impairment. Retrieved January 10, 2020, from http://www. who.int/ageing/publications/guidelines-icope

Wulandari, T. S., \& Ismail, S. (2019). Exploring nurses' experience of managing attention and mood in post-stroke patients: A qualitative study. Jurnal Keperawatan Padjadjaran, 7(2). https://doi.org/10.24198/ jkp.v7i2.1000

Yoo, C., Yong, M. H., Chung, J., \& Yang, Y. (2015). Effect of computerized cognitive rehabilitation program on cognitive function and activities of living in stroke patients. Journal of Physical Therapy Science, 27(8). https://doi.org/10.1589/jpts.27.2487 